\title{
An International Journalism Model of Professionalism in News Production: The Concepts and the Measurements
}

\author{
Khalaf Tahat \\ Yarmouk University, Irbid, Jordan
}

\begin{abstract}
This study aimed to contribute in establishing an international journalism model of professionalism in the production of the news. The main purpose is to explore the degree to which this model predicts the professional values in the media content. In particular, this model was tested on the content of a leading news organization in the Middle East, Al Jazeera, to identify whether or not Al Jazeera reflected professional values in news production or other non-professional values. A total of 592 news stories-234 from AJE and 358 from AJA—published from January 1, 2014, to April 30, 2014, were analyzed. The findings of this study indicate that Al Jazeera reflects professional values to a substantial degree. The professional values were reflected highly and nearly two thirds of the stories had professional values in the content. The chi square tests shows there are frequency/percentage differences, but overall the patterns are similar, with no statistically significant differences in the AJA and AJE. Scholarly implications, future studies and limitations were presented in this study.
\end{abstract}

Keywords: professionalism, international journalism, content analysis, Al Jazeera

Many leading world news organizations have targeted different audiences and designed specific content that meets their outside audiences' needs (Foote, 1995). For example, CNN, based in the U.S., has news websites in nine different languages; the BBC, based in London, has news websites with 27 different languages; Voice of America broadcasts in "40-50 languages" (Mody, 2012, p. 103) and Al Jazeera (AJ), based in Qatar, has three news websites, one in English (AJE), the other in Arabic (AJA), and the third one in Turkish (CNN news website, 2012; BBC Arabic website, 2012; Al Jazeera English website, 2012).

These international news websites are very clear in saying that they present their news production from their audiences' perspectives and with professional values. For example, CNN claims that the "CNN.com relies heavily on CNN's global team of over 4,000 news professionals". Similarly, the BBC Arabic news website mentions that the main mission of its website is to put Arab interests and needs at the center of its concerns (BBC Arabic website, 2012).

This study is important because it establishes, for the first time, an international journalism model in the production of the news to measure professionalism construct when the same news organization communicates to two or more audiences that have different cultural, social, language, and interest backgrounds. Thus, this study aims to contribute in overcoming the non-systematic ways of judging any news organization, by developing a scientific way based on testing the professional values on the content of a news organization to find out what professional values were more prevalent in news production.

Khalaf Tahat, Ph.D., Assistant Professor, Mass Communication College, Yarmouk University. 
Another reason that makes this study important is the nature of Al Jazeera itself and the unknown model that it uses in news production. Al Jazeera is one of the most controversial news organizations in the modern history of the media. Different perspectives from scholars, politicians, media observers, official reports, and commentaries revolve around $\mathrm{AJ}$ and its true goals in the international media system. The first perspective views $\mathrm{AJ}$ as free, independent, objective and adopting Western professional values in news production (Boyd-Barrett \& Xie, 2008; El-Nawawy \& Iskandar, 2003; Quinn \& Walters, 2004); the second trend views AJ as lacking objectivity, biased to the Arab and Muslim interests against the West, and supporting fundamentalist groups in the Middle East in its daily reporting (Ajami, 2001; Campagna, 2001; Darwish, 2001, Lynch, 2005; Negus, 2001; Wojcieszak, 2007; Zednik, 2002).

\section{Statement of the Problem and the Purpose}

The problem of this study is that in an era of global communication little is known, through systematic study, about the role of professional values in news production when the same news organization communicates to different audiences that have different interests, religious, and cultural backgrounds through content in multiple languages.

The main purpose of this study is to test a new proposed professional model by applying it to the content of a non-Western news organization as well as to explore the degree to which this model predicts the type of media content patterns. In particular, this study examines how a leading news organization in the Middle East, Al Jazeera, frames its news in two languages when it targets readers from different cultures. Thus, this model was tested to identify whether or not AJ reflected professional values in news production or other non-professional values.

This study came as a response to researchers' calls to conduct more studies to explore the main trends of news production and consumption in different areas in the world (Elareshi \& Gunter, 2012). Also other academics have urged that more studies should be conducted in order to arrive at a fuller understanding of multilingual news coverage in global news production (Abudl-Mageed \& Herring, 2008). Besides, this study addresses the question that has arisen about whether or not AJ has an ideological balance in its news websites (Abudl-Mageed \& Herring, 2008). It also addresses the suggestion by Zeng and Tahat (2012) that future research "compare the trends of coverage between the Arabic version and English version of the same news organization" (p. 445).

To explore the problem presented in the introduction, the next sections are organized as follows. Section two includes the literature review and discusses these concepts: professionalism in journalism from normative theory perspectives, and the main professionalism values. The research questions are presented in the end of section two. The study design, methodology and measures are explained in section three. The results are presented in section four. And finally, discussion and conclusions about the results are offered in section five.

\section{Literature Review}

This section defines the meaning of the profession of journalism and discusses the roots of the professionalism model. In particular, the professional values of journalism are described through normative theories of the press.

Professionalism refers to "an organizing principle of an occupational cohort. The professional's work is based in a theoretical body of knowledge, shared values and norms, and common purpose" (Gade \& Lowrey, 
2011, p. 30). As a profession, journalism is based upon the general value of upholding democracy through providing citizens the information they need to self-govern (Kovach \& Rosenstiel, 2007, p. 17). Furthermore, if the basic logic of the profession in journalism lies in its mission to help people be good, informed citizens, then that mission should reflect itself in content that allows the citizens to be more informed, more knowledgeable, and give them many different ideas and perspectives (Kovach \& Rosenstiel, 2007, pp. 15-32). Defining the profession of journalism leads to a discussion the roots of professional values, in particular, normative theories, namely, libertarian theory and social responsibility theory.

Libertarian and social responsibility theories. Normative theories of the press describe an ideal way for media systems, addressing what the press should and should not do (Baran \& Davis, 2006). Siebert (1956) argued that libertarian theorists believe that all types of information should be made public. Under the libertarian concepts, the media's main purpose is to help discover truth and solve the political and social problems in the society by presenting and providing all opinions as the basis for decisions (Siebert, 1956). This theory also assumes a multiplicity of voices reaching the public. The libertarians assume that every person has the same opportunity, if not the same ability of access to media. In this case, every person has the right to express him/herself, if he/she has something to say, regardless whether the content is true or false (Siebert, 1956, p. 51). This theory also stresses the rejection of any kind of government monopolies over mass communication; however, this assumption means that media is privately owned and competes in an open market (Siebert, 1956, p. 52). The libertarians argue that "anyone, citizens or alien, who had the inclination, should have the unrestricted opportunity to own and operate a unit of mass communication" (Siebert, 1956, p. 52). Media in democratic societies are free of government control or intervention; the public provides control only through the "self-righting process" and through the idea of "the market place of information" (Siebert, 1956, p. 53).

As for the social responsibility theory, Ostini and Fung (2002) argued that "the core of this theory is based on the notion that the media have a moral commitment to society to provide adequate information for citizens to make informed decisions" (p. 42). The fact is that the faith in virtually "absolute freedom" and that "the nature of man carried built-in correctives" (Peterson, 1956, p. 77) were diminished and new standards of press performance began to link responsibility with freedom; therefore, codes of ethical behavior were formulated (Peterson, 1956). This theory emphasized that if people are to remain free, they must live by reasons instead of passively accepting what they see, hear, and feel. Therefore the more alert elements of the community must goad them into the exercise of their reason. Without such goading, people are not likely to be moved to seek truth. People's aim is not to find truth but to satisfy their immediate needs and desires (Peterson, 1956, p. 100). Thus, because man is not prone to use rationality, it becomes necessary for the press to report the "truth about the facts" (Peterson, 1956).

Journalists, under these theories, have a freedom to say whatever they want without any constraints to serve society (Merrill, 1974). Therefore, "truth is what journalists consider fit to call truth, just as news is what they decide is news-nothing more and nothing less" (Merrill, 1974, p. 167). After reviewing the roots of professionalism in normative theories, the following paragraphs briefly summarize the most important professional values.

Professionalism main concepts. Professionalism in journalism is summarized as a "number of discursively constructed ideal-typical values, journalists feel that these values give legitimacy and credibility to what they do. The concepts, values and elements are said to be part of journalism's ideology" (Deuze, 2005, p. 
446). According to other scholars, these professional values include public service, fairness, independence, allegiance to truth, journalistic autonomy, inclusivity, impartiality, objectivity (Gade, 2011; Hitchens, 2007; Kovach \& Rosentiel, 2007; Weaver et al., 2007), and journalists view their social responsibility functions as being interpreters, watchdogs, disseminators, and populist mobilizers (Weaver et al., 2007).

Deuze (2005, p. 447) summarized that the professionalism values in journalism have been identified by other journalism scholars (Beam, Weaver, \& Bronlee, 2009; Golding \& Elliott, 1979; Kovach \& Rosenstiel, 2007; Merritt, 1995) and are grouped to five: public service, objectivity, autonomy, immediacy, and ethics (Deuze, 2005, p. 447). The following paragraphs shed some light on specific professional values by focusing on their definitions as professional concepts. In particular, objectivity, factuality, fairness, and public service are discussed shortly (see Figure 1).

Objectivity. Schudson (2001) defined objectivity as a norm by which journalists separate facts from values and report only the facts. Objective reporting should not be emotional in tone. Based on the objectivity concept, the journalist should report "news" without commenting on it or slanting it. Assertions that refer to facts are regarded as "objective" and, therefore, valid; whereas the judgments related to human affairs in which values play a leading role are "subjective" (Ward, 2008, p. 19) (see Figure 3). Objectivity is a very important value to journalists, because value judgments, inasmuch as they distort reality, are deemed bad. Instead, the right thing for journalists is trying to be neutral, keeping equal distance from contending sources, because inserting one's opinions in a story is "risky" (Rich, 1997, p. 204). Objectivity means that journalists exclude themselves when reporting on societal issues by setting aside their own ideas and opinions (Munoz-Torres, 2007). Hackett (1984) also pointed out that objectivity suggests that facts can be separated from opinions or value judgments, and that journalists can stand apart from the real-world events whose truth or meaning they transfer to the news audience by means of neutral language and competent reporting techniques (p. 232). Furthermore, MacLean (1981, p. 56) suggests that "When a story does not distinguish clearly between its author's interpretations and the facts being reported, it is a biased or slanted report". Donsbach (2003) summarized the main elements of objectivity in three things: first, separating facts from opinion; second, presenting an emotionally detached view of the news; and third, striving for fairness and balance (p. 384). Stensaas (1986) said that for a news story to be objective it should contain these elements: it includes only verifiable assertions, does not make claims to significance, and avoids statements of prediction, value, advocacy, or inductive generalizations without clear attribution to source (p. 53). According to the principle of balance, the goal of good reporting is to present multiple, or even opposing, views about a topic, as if they were all equally valid, that is, without giving privilege to any of them (Klaidman \& Beauchamp, 1987, p. 46). This study used attribution as indicate of objectivity in media content .

Factuality. It means that reporters should base their news stories on facts, as facts can be easily verified (Reese, 1990; Condit \& Selzer, 1985; Ryan, 2001) (see Figure 3). Journalists establish factuality in different ways, first, by using credible sources who make statements that can be quoted as fact without further investigation. Second, journalists also produce factuality through their peculiar means of making the accounts of sources seem objective (Ericson, 1998). Facts are clearly attributed to official sources, often in point-counterpoint format. These attributions make the journalists seem to be operating in a detached, impartial, independent, fair, and balanced manner (Ericson, 1998, p. 86). News production is a perpetual process of authorizing facts through sources (Ericson, 1998, p. 86). Altmeppen, Arnold, and Kcossler (2012) said that impartiality in news is expected to be presented in a neutral way, without subjective evaluations and without 
being mixed with comment (p. 338). Factuality will be measured by examining the extent to which the facts (Who, what, when, and where) are present before the opinions in the news story.

Fairness. As for the concept of fairness, Simon, Fico, and Lacy (1989) defined fairness of source usage as the inclusion of statements from sources representing all sides of a story; therefore, presenting or not the sides of the event in the news story was used to measure fairness (see Figure 3).

Public service. The concept of public service is often coupled with references to journalism's normative roles in educating the public or community, in helping society function properly, in taking actions to benefit the public, in serving a community generally or in serving various groups in a community (Beam et al., 2009). News organizations with strong professional orientation are likely to be ones where public service is important. And a news organization that is perceived to be market driven tends to get lower evaluations on its public service commitments (Beam et al, 2009). Below are some related studies that had been conducted on some of the above mentioned professional norms.

Fico and Cote (1999) analyzed the content of newspapers to examine how fair their news coverage of the 1996 presidential election was. Operationally, Fico and Cote defined story fairness as the presence of quoted or paraphrased assertions by sources supporting both Clinton and Dole. The proportions of one-sided and two-sided stories address the probability of readers' exposure to individually fair or unfair story coverage, and whether there is an equal chance of encountering "unfair" stories dominated by each candidate. Fico and Cote found that the news coverage was imbalanced and favored Dole (62 percent) over Clinton (33 percent) and only 5 percent of the news coverage was balanced for both sides.

Also, Fico and Soffin (1995) examined 259 news stories for how many sources were cited on each side of a controversy. They examined whether sources were cited in the headline, first paragraph, and/or graphics, and whether both sides were cited within the first five paragraphs of the story. They found that around half of the news stories were absolutely one-sided in their presentation of a controversy, and only seven percent of the news stories were entirely balanced (p. 626). However, this study examined the value of fairness in AJ content by examining whether or not AJE and AJA presented two sides of the news story. Also, the sourcing was used in this study as a measure of professionalism. In this case, the more sources used in the news story the more professional values in the story are. In another example, using judgments or interpretation statements in the news story doesn't match with the professionalism standards to be objective. Pan and Kosicki (1993) pointed out that by using for example, "Iraqi dictator", inside the story this means that a news report places Saddam Hussein in the same category with Hitler, Noriega, Stalin, and other generally hated men in American culture. Also, they mentioned that by designating the 1989 uprising in China as a "prodemocracy movement", news reports interpreted the meaning of the uprising and categorized it in the same general category that the American Revolution might belong (p. 62). This study looked at the entire body of the news stories for attribution usage to examine how objective the story was in AJE and AJA.

Altmeppen and his colleagues (2012) pointed out that free and independent press should be able to reflect the diversity of a pluralistic society. Journalists are expected to present a wide range of issues, subjects, views and opinions. The diverse groups of society must have access to the media, and journalists should have access to a wide range of news sources (p. 337). This study examined to what extent each news story included wide range of views from different perspectives and many sources. This counted the number of sources used in the story.

Overall, the professional model treats people as "citizens and helps them participate in civic activity" (Rosen, 2000, p. 680). Journalism values direct journalists to the idea that journalists have kind of a democratic 
mission of "public service" (Kovach \& Rosenstiel, 2007). In other words, the main mission of journalism is to give the people the information they need to be good citizens, so that they can participate in government and democracy (Kovach \& Rosenstiel, 2007). Lewis (2006) asserts the importance of informed citizenship by "quality information that people should receive about politics and public affairs" (p. 304).

In sum, most studies in the literature widely discussed, conceptually, the main values of professionalism in journalism (e.g., Deuze, 2005; Johnson \& Kelly, 2003; Hitchens, 2007; Kovach \& Rosentiel, 2007; Siebert, 1956, Peterson, 1956, Weaver, Beam, Brownlee, Voakes, \& Wilhoit, 2007), but, empirically, few of them tested these values of professionalism (e.g., Beam, Weaver, \& Brownlee, 2009; Fico \& Soffin, 1995; Johnson, Slawski, \& Bowman, 1972; Pan \& Kosicki; 1993) (see Figure 2 about the related studies). Also, most studies in the literature examined journalism professional values by focusing on journalists' attitudes and their perceptions, so this study adds to the body of literature of the journalism professionalism measurements by examining professionalism through content analysis method. In other words, this study uses media contents as indicators to measure the journalism professionalism in news production instead of depending on journalists' perceptions. In addition, this study directly examines journalism professionalism in areas outside the U.S. and Europe. Besides, most studies on professionalism focused, separately, on only one element of professional values (e.g., fairness value, or objectivity value, etc.); however, this study uses four professional values together and tests them in the same news content at the same time. Finally, the content of newspapers and television had previously been researched, but there was no single study that paid attention to these professional values in news websites. So, this study fills this gap in studying professional values in online media content. This study examines professionalism in news production in the Middle East through analyzing the content of one of the most controversial non-Western networks, Al Jazeera.

Based on the literature review this study asked these questions and posed three hypotheses, specifically:

RQ1a: To what extent was the professional model of news production apparent in AJA?

RQ1b: To what extent was the professional model of news production apparent in AJE?

RQ1c: Was there a significant difference between AJA and AJE in the extent to which the professional model was apparent?

\section{Methodology}

Content analysis was used to test these this model. Berelson (1952) defines content analysis as a "research technique for the objective, systematic, and quantitative description of manifest content of communication" ( $p$. 489). Content analysis is used frequently in all areas of the media. The method is popular with mass media researchers because it is an efficient way to investigate the content of the media (Wimmer \& Dominick, 2011, p. 156). Content analysis helped to tell whether or not a news story reflected professional values such as objectivity, fairness, and factuality.

\section{Population, Sample, and Unit of Analysis}

There are hundreds of news websites in the Arab world, the majority in the Arabic language and a few in English. This study focused on the AJE and AJA versions of the news websites: AJE (www.english.aljazeera.com) and AJA (www.aljazeera.net). These two news sites were selected for several reasons. First, they are considered the most important news websites in the Middle East with the highest readership among all news websites (Galal, Galander, \& Auter, 2008). They are considered an influential agenda setter in their respective geographic region. In addition, they represent a variety of Arab and non-Arab 
world cultures and perspectives, as well as different political ideologies (El Nawawy \& Powers, 2008; Galal, Galander, \& Auter, 2008).

The population of the study was defined as: All content that was published on the homepages of AJA and AJE from January 1, 2014, until April 30, 2014. Al Jazeera websites had similar, but not identical, news sections. Since the online content of the news websites continuously changes, and following Massey and Levy (1999) in their study of the English-language online newspapers in Asia, both websites were accessed twice within 24 hours.

The news story was the unit of analysis. The study focused on the text of the stories. Audio, opinions, shows, photos, schedules, and trending topics were excluded from analysis.

Constructed week sampling was used, the sample was stratified by day of the week, and 50 percent of the content of each day was randomly pulled by using interval systematic procedure. Constructed weeks have been the most convincing response to the problem of systematic content variation in media content (Riffe, Lacy, \& Fico, 2005). Two constructed weeks were used to draw the sample of news stories collected in four months from AJE and AJA news websites. One constructed week adequately predicts and represents the population, and two constructed weeks works even better (Riffe et al., 2005, p. 98). In a constructed week sample, all Sundays are identified and then the researcher randomly selects one Sunday, then a Monday, a Tuesday, etc., until all seven days of the week are represented equally (Riffe, Aust, \& Lacy, 1993; Riffe, Lacy, \& Drager, 1996).

There were 17 weeks of the time of the study [January 1 until April 30, 2014]. A computerized random number generator (https://www.random.org/) was used to generate two random numbers between 1 [first week of the study] and 17 [last week of the study]. For example, the computer generated these two numbers, 2 and 4 weeks, of the 17 weeks. This means that Sunday of 12th of January was the first Sunday in the sample and 26th of January was the second Sunday. So, in this case the researcher looked at all the content of these two Sundays which together had a total of 99 stories for the AJA (e.g., in AJA and in the first Sunday January 12th there were 48 stories, and in the second Sunday of January 26th there were 51 stories). And the same procedure was done for Mondays, Tuesdays, etc. until the coder went through the entire 14 days. Each story for each day was assigned a number. Based on this procedure, the total number of the initial sample yielded 701 stories for AJA and 464 stories for AJE. Fifty percent (50\%) of the total number of each day was pulled through interval systematic sample. In this study every 2 nd [randomly] story was selected from each day list sample. A systematic random sample of 358 stories from AJA news stories was selected, and the same sampling procedure yielded 234 stories constituting the AJE sample. The goal of pulling 50 percent was to get a substantial, reasonable sample size that had adequate power for the study.

\section{Time Frame}

As previously noted, the time frame of this analysis was from January 1, 2014, until April 30, 2014. Riffe et al. (2005) suggested that in content analysis research there is no need to sample an entire year. The four-month period means that the coder cannot generalize to the entire year, however, the time frame was long enough to include numerous news events of international interest to reveal whether (and how) the news organization communicates to its main two audiences (Arab world and the West). Also, since this study discussed how a news organization communicates to multiple cultures through different products, it was not a time-sensitive question. Thus, the four-month period was used as the time frame for this study. This time frame 
witnessed many important events that most news organizations would pay attention to during their daily coverage.

\section{Construct, Dimensions of Measurements, and Data Analysis}

The study suggested a professional model in news production could be used by news organizations. The following paragraphs address this model in terms of its conceptual definition and operational definition.

Objectivity means that journalists exclude themselves when reporting on society issues by setting aside their own ideas and opinions (Munoz-Torres, 2007). Attributing statements to sources is a key element of the objective ritual. Journalists use attributions to indicate their objectivity (to account for the value-laden statements and opinions in the content and make clear where these views come from). This variable was coded as: $0=$ no attribution in story, $1=$ partial attribution, 2 = full attribution. To determine when to code no attribution or partial attribution or full attribution, the process of coding depended on the situations of presenting none, or some or all facts/ideas/opinions in the story with attribution. For example, partial attribution is when attribution is used in some cases, but some facts/ideas/opinions are presented without attribution. Also, full attribution is used when all facts/ideas/opinions are presented with attributions. Finally, when the ideas/opinions in the story has no attributions at all, then it was coded as no attribution. The frequencies and percentages were calculated, and used to decide how to interpret this measure (no attribution to full attribution). This means that the more attributions used in the story, the more it is objective, the more it reflects professional values (see Figure 4).

Fairness is defined as presenting both sides of the event in the news story (Simon et al., 1989). "The side" refers to the attributed sources in the news story. In this study, a dichotomous measure was developed to measure the fairness variable. If both sides of the story had been told in the story it would be coded as 1 , and if the story did not present the two sides it would be coded as 0 . Also, any story that has more than two sides it was also coded as 1 . Frequencies and percentages were used to interpret when to say the story was fair in its reporting or not (see Figure 4).

As for the sourcing variable, the term "source" refers to all people and inanimate sources that are used in the news story and directly or indirectly quoted in the title, headline, lead, or the main text of the story. Sources include those who are paraphrased and those who provide actualities. They are identified through attribution that include the words "said", "say", "told", "informed", "announced", "urged", etc. In other words, the source must have a speaking part in the story (Foote \& Gade, 2006). To measure the degree to which the news story cited sources directly or indirectly (human or inanimate sources); four categories were designed to measure this variable: if the news story did not cite any sources it was coded as zero sources $=0$; if it cited only one source then it was coded as 1 , if it cited two sources it was coded as 2, and if it had more than 2 sources it was coded as 3. What's most important was that a story (typically) has more than one source, representing some effort to confirm information or provide a different perspective or additional information. The more sources cited, the more professional the news story was considered to be. Frequencies and percentages were used to interpret the data in this variable (see Figure 4).

Finally, the professional news is a "factual presentation" of events deemed newsworthy (Condit \& Selzer, 1985; Hackett, 1984). Factuality should be based on facts, which are phenomena that can be observed and demonstrated as the basis of the story. If the Who, What, When, and Where are present before the story provides an interpretation of these facts, then the story is more fact-based. However, because Why and How 
concepts are often interpretive and provided by sources, they would not be coded in the story. The other four elements describe everything basic and important to readers of a news story. The who question defines who are the people involved? What defines as what happened or happens? Where means where did/does this event take place? When defines as when in time did/does this take place? Factuality was measured by examining the extent to which the facts (Who, what, when, and where) are present before the opinions in the news story. To measure this variable: $0=$ opinion present before any facts (who, what, when, where) presented; 1 = opinion presented before all facts presented; and $2=$ all facts presented BEFORE an opinion was presented. Opinion is a viewpoint, statement, or judgment about a matter/event normally regarded to be subjective because opinion rests on grounds not enough to produce absolute certainty, and opinion is the result of interpretation of facts or emotion. Frequencies and percentages were used to interpret the data. This way the higher measures reflected greater factuality, or that the basic facts were present before opinions, which should reflect that the story was fact-based (see Figure 4).

This way, the researcher developed an index to measure the professionalism model that was aggregated from the values allocated to the criterion variables of professionalism where each dimension of professionalism has its own values. The highest value meant that the story reflected more professional values and vice versa. So, each story was coded based on the aforementioned four measures of professionalism: objectivity, fairness, factuality, and finally, the use of sources. The index of professionalism ranged from 0 points, corresponding to a lowest level of professionalism, to 8 points, corresponding to the highest level of professionalism. After presenting all of the variables related to professionalism in journalism, the researcher would be able to judge the degree to which the news story reflects the elements of the professionalism values.

To explain in more details, let us say, hypothetically, that coding of a news story showed these values: 2 on the objectivity measure, 1 on fairness, 2 on factuality, and 2 on the use of sources. In this case, all values were summed up and this yielded 7 points on the index [0-8]. The point of 7 could be explained in this way: a 7 reflected a story that included a high level of professionalism. The same analysis was done for both AJA and AJE (see Figure 5). To answer these RQs the researcher summed the measures to each variable in the model and assessed whether the sum of the measures reflected a low, medium or high presence of the measures. Chi square tests were used to determine whether there were significant differences on the variable measures by language version of the web site (AJA and AJE), and whether the total model scores differed by web site. Also the researcher ran chi square tests on the model index scores to test for differences by web site in the overall model. In this test, the average of each index in AJE and AJA was used and the significant level was set at 0.05 to determine the significant differences between AJA and AJE.

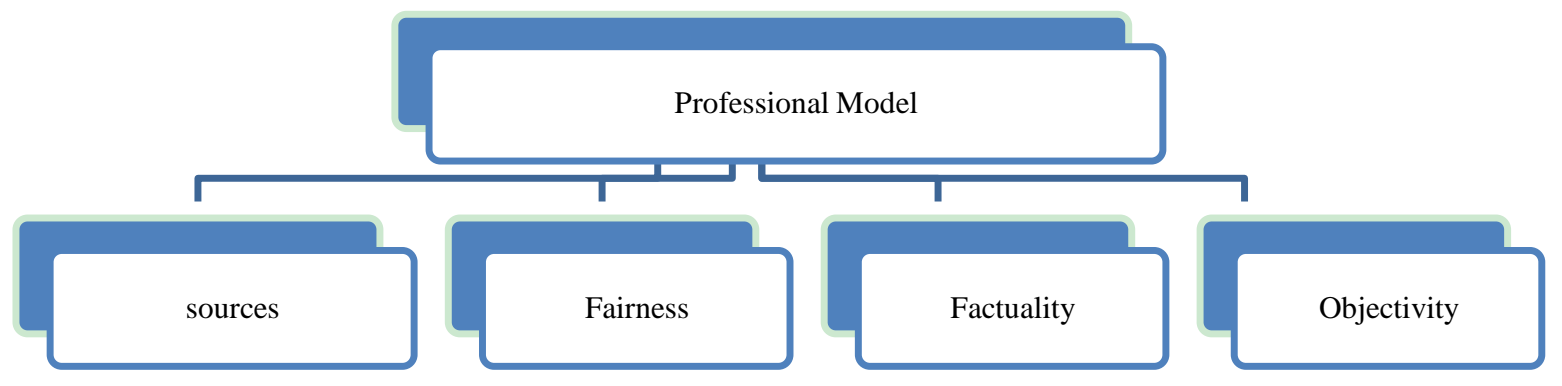

Figure 1. Professional concepts. 


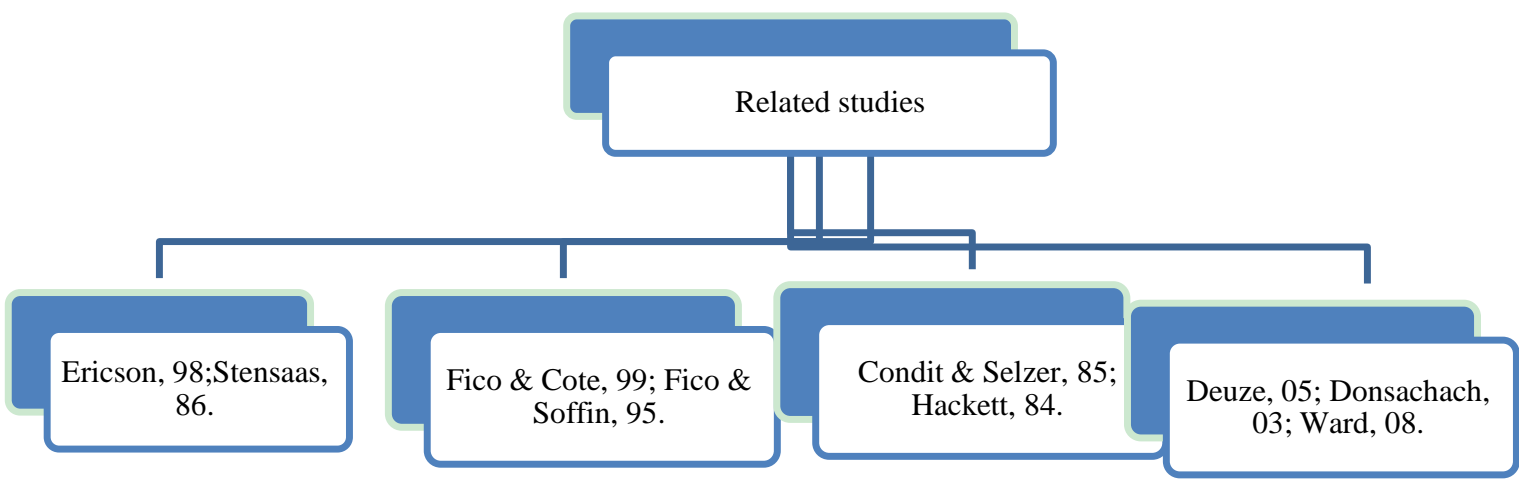

Figure 2. Related studies.

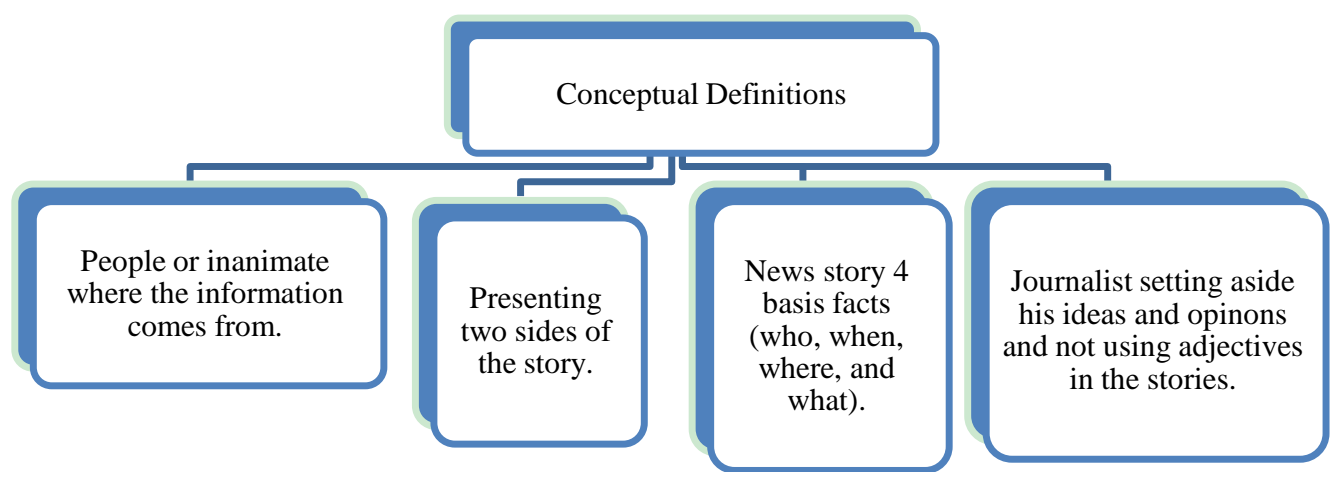

Figure 3. Conceptual definitions.

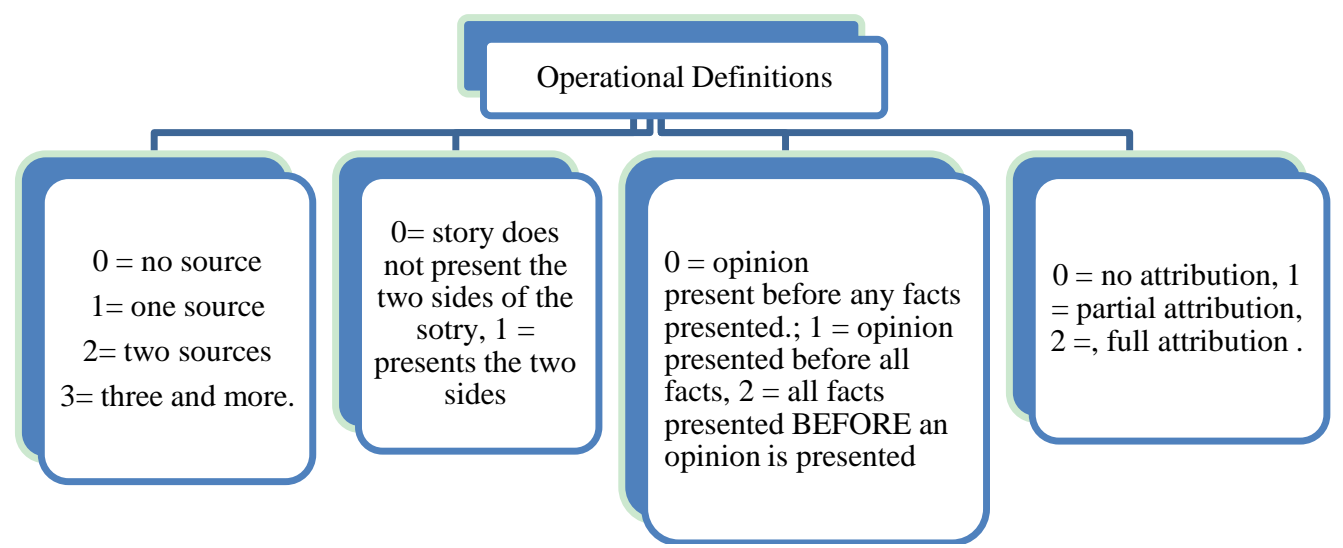

Figure 4. Operational definitions.

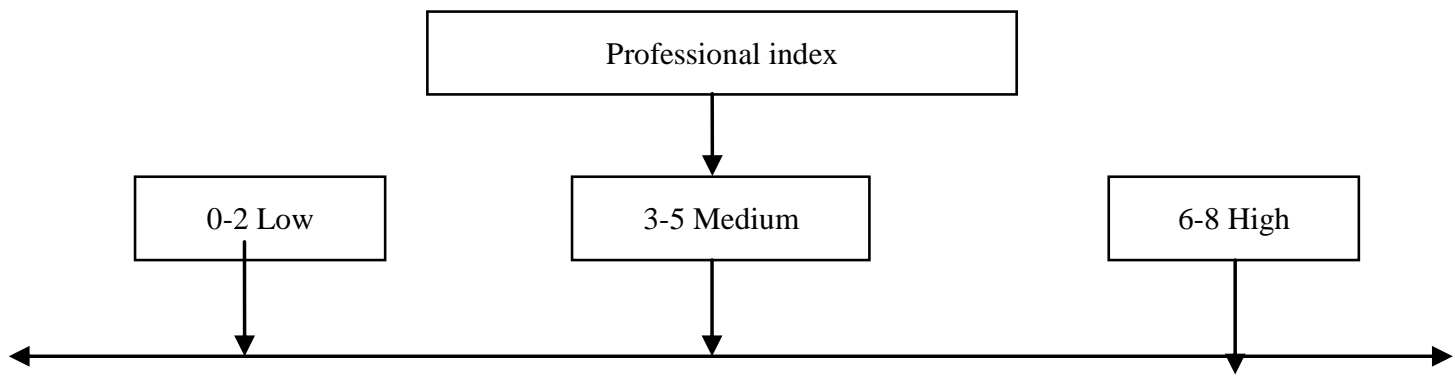

Figure 5. Professional index. 


\section{Inter-coder Reliability}

The two websites of Al Jazeera were written in two different languages; in Arabic and in English. The inter-coder reliability was calculated for both languages. Two other coders, one of them speak Arabic professionally, helped the author of this research. The author of this study spent 9 to 11 hours with graduate students, separately, to train them on how the codebook worked. When an approximate percentage of agreement on coding decisions reached 80 percent, then the additional coders each coded independently, 24 stories in English and 35 in Arabic (about 10 percent of each sample). Inter-coder reliability was calculated using Cohen's kappa, which calculates expected agreement between two coders (Riffe et al., 2005, p. 151). Cohen's kappa coefficients range from 0 to 1 , with a calculated value of 0.75 or above acceptable (Wimmer \& Dominick, 2011, p. 175). The intercoder reliability for the Arabic stories ranged from 0.76 to 1.0 , and for the English stories from 0.82 to 1.0. The Cohen's Kappa coefficients for the Arabic and English stories are shown in Table 1.

Table 1

Intercoder Reliability Results for Arabic and English Stories

\begin{tabular}{lll}
\hline Variables & Cohen's Kappa for AJA & Cohen's Kappa for AJE \\
\hline Objectivity & 0.76 & 0.82 \\
Fairness & 0.94 & 1.00 \\
Sourcing citation & 1.00 & 1.00 \\
Factuality & 0.79 & 0.86 \\
\hline
\end{tabular}

\section{Results}

This study examined the professional values that are more prevalent in the content in AJA and AJE when they communicate to their audiences that have different cultural, language, and interest backgrounds. A total of 592 news stories—234 from AJE and 358 from AJA—-published from January 1, 2014, to April 30, 2014, were analyzed. The number of stories published varied by month, ranging from 90 stories in April to 221 stories in March.

\section{Research Question 1 (a)}

Research Question 1(a) in this study asked to what extent the professional model of news production is apparent in AJA.

The professional values were reflected in high level in AJA stories. The mean of professional values for AJA stories on the professional index was 5.98 out of 8 points $(S D=1.48)$, placing it 0.02 of a point short of the high level of 6 to 8 . The data in Table 2 indicated that about two thirds ( $n=233,65.1$ percent) of the published stories in AJA reflected a high level of professional values, over a quarter ( $n=119,33.2$ percent) of the sample reflected a moderate level of professional values and few stories $(n=6,1.7$ percent) reflected a low level of professional values in their coverage. By examining the variables that comprise the professional model (objectivity, fairness, sourcing, and factuality), the data show that AJA tended to embed professional values at somewhat differing levels in its news production.

The first value to be discussed in the professional model is objectivity. Nearly half ( $n=169,47.2$ percent) of the stories in AJA included full attribution, about equally likely to include partial attribution $(n=168,46.9$ percent), and few stories ( $n=21,5.9$ percent) seldom included no attribution. Also, the data about the fairness value showed that AJA tended to reflect this value in its coverage to a high degree. The vast majority of the stories ( $n=265,74$ percent) in AJA presented two sides of the event in the story, and about a quarter ( $n=93$, 26 percent) of the published stories did not present two sides of the event. As for the sourcing use value, the 
overwhelming majority ( $n=315,87.9$ percent) had two or more sources, just over a tenth $(n=41,11.5$ percent) had one source, and very few stories ( $n=2,0.6$ percent) did not cite any sources. Factuality is the last value in the professional model. The AJA tended to be a fact-based news website. Over half ( $n=206,57.5$ percent) of the analyzed stories presented all facts before an opinion was presented, but in more than a quarter $(n=96,26.8$ percent) of these stories an opinion was presented before any facts, and about a sixth ( $n=56,15.6$ percent) of the published stories presented opinion before all facts were presented.

Table 2

The Professional Index Values in AJA and AJE

\begin{tabular}{lcccccc}
\hline & \multicolumn{2}{c}{ AJA $(N=358)$} & \multicolumn{2}{c}{ AJE $(N=234)$} & \multicolumn{2}{c}{ AJA \& AJE $(N=592)$} \\
\hline The professional Index & frequency & percent & frequency & percent & Total & percent \\
\hline Low values (0-2) & 6 & $1.7 \%$ & 16 & $6.4 \%$ & 21 & $3.5 \%$ \\
Middle values (3-5) & 119 & $33.2 \%$ & 73 & $31.2 \%$ & 192 & $32.4 \%$ \\
High values (6-8) & 233 & $65.1 \%$ & 146 & $62.4 \%$ & 379 & $64 \%$ \\
$M(0-8)$ & & 5.98 & & 5.88 & 5.93 \\
Total & 358 & 100 & 234 & 100 & 592 & $100 \%$ \\
\hline
\end{tabular}

Notes. $X^{2}=5.991, d f=2, p .=0.060 . M$ of professional index in AJA $=5.97, S D=1.48$, in AJE $M=5.87, S D=1.75$.

\section{Research Question 1 (b)}

Research Question 1(b) in this study asked to what extent the professional model of news production is apparent in AJE. The professional values were reflected in high level in AJE stories. The mean of professional values for AJE stories on the professional index was 5.88 out of 8 points $(S D=1.75)$, placing it 0.12 of a point short of the high level of 6 to 8 . The data indicated a little less than two third ( $n=146,62.4$ percent) of the published stories in AJE reflected a high level of professional values, about a third ( $n=73,31.2$ percent) reflected a moderate level of professional values and few stories $(n=16,6.4$ percent) reflected a low level of professional values in their coverage. Frequencies and percentages for each of the four individual professional values show that AJE, like AJA, tended to embed these professional values in the production of its news, though at somewhat differing levels. For the objectivity value, nearly over half ( $n=124,53$ percent) of the stories had full attribution, about two fifths ( $n=101,43.2$ percent) included partial attribution, and very few stories included no attribution ( $n=9,3.8$ percent). Also, the data show that AJE tended to be fair in its coverage.

Fairness is the second value in the professional model. The data show that large majority $(n=166,70.9$ percent) of the stories in AJE tended to present two sides of the event, and less than a third ( $n=68,29.1$ percent) of the published stories did not present two sides of the event. As for the sourcing use value, AJE provided its readers with whatever from multiple sources. The majority ( $n=156,66.7$ percent $)$ of the published stories cited three or more different sources, around a fifth $(n=47,20.1$ percent $)$ provided two different sources, just over a tenth ( $n=26,11.1$ percent) had only one source, and very few stories ( $n=5,2.1$ percent) had no sources. The last professional concept is factuality, and over half ( $n=124,53$ percent) of the analyzed stories presented all facts before an opinion, but in more than a quarter $(n=69,29.5$ percent) of these stories an opinion was presented before any facts, and about a sixth $(n=41,17.5$ percent $)$ of the published stories presented opinion before all facts were presented.

\section{Research Question 1 (c)}

Research question 1(c) asked if there is a significant difference between AJA and AJE in the extent to 
which the professional model is apparent. As the data analysis shows in Table 3, at a broad level there were no significant differences between the two sites in terms of employing professional values in news production $\left(X^{2}\right.$ $=5.991, d f=2, p=0.060$ ). Both sites, as data in Table 3 show that there are frequency/percentage differences, but overall the patterns are similar, with no statistically significant differences. The professional values were reflected highly and nearly two thirds ( $n=379,64$ percent for both sites together) of the stories had professional values in the content ( $n=233,65.1$ percent for AJA, and $n=146,62.4$ percent for AJE), and about a third ( $n=192,32.4$ percent for both sites) employed a medium amount of professional values $(n=119,33.2$ percent for AJA, and $n=73,31.2$ percent for AJE). Only a small percentage of stories on the two sites ( $n=21$, 3.5 percent) reflected a low amount of professional values in the published news stories $(n=6,1.7$ percent for AJA, and $n=16,6.4$ percent for AJE). Also the means for the professional value index were nearly the same: 5.98 for AJA and 5.88 for AJE.

Another way to examine the differences in the professional model is to look at the Chi square test of each value between the AJA and AJE. As the results displayed, the four variables of the professional model had frequency/percentage differences, but overall the patterns are similar, with no statistically significant differences. There is no significant difference in using objectivity values between AJA and AJE were identified $\left(X^{2}=2.537, d f=2, p=0.281\right)$. As for the fairness value, the analysis of data in revealed that there was no significant difference in presence of the fairness value between AJA and AJE $\left(X^{2}=0.0679, d f=1, p .=0.410\right)$. In addition, there was no significant difference between AJA and AJE in terms of the sources they cited and provided in their published stories $\left(X^{2}=6.317, d f=3, p=0.150\right)$.

Table 3

Factuality Value in AJA and AJE

\begin{tabular}{lcccccc}
\hline & \multicolumn{2}{c}{ AJA $(N=358)$} & \multicolumn{2}{c}{ AJE $(N=234)$} & \multicolumn{2}{c}{ AJA \& AJE $(N=592)$} \\
\hline Factuality & Frequency & Percent & Frequency & Percent & Total & percent \\
\hline Opinion present before ANY facts presented. & 96 & $26.8 \%$ & 69 & $29.5 \%$ & 165 & $27.9 \%$ \\
Opinion presented before ALL facts presented & 56 & $15.6 \%$ & 41 & $17.5 \%$ & 97 & $16.4 \%$ \\
all facts presented BEFORE an opinion is presented & 206 & $57.5 \%$ & 124 & $53 \%$ & 330 & $55.7 \%$ \\
Total & 358 & 100 & 234 & 100 & 592 & 100 \\
\hline
\end{tabular}

Notes. $X^{2}=1.193, d f=2, p=0.551$.

Finally, as for the factuality value, the data in Table 3 indicated that there was no significant difference between AJA and AJE in terms of employing the factuality value in their published stories $\left(X^{2}=1.193, d f=2\right.$, $p=0.551)$.

In short, the indices reveal a story mean of 5.88 and 5.98. Both approaching, but falling slightly below the "high" range of professionalism. The measures reveal more specifics on where the stories fell short of high professionalism: nearly half the stories were not fully attributed; about one-quarter of the stories lacked balance, presenting one side only of an issue, and about one-quarter of the stories reported opinions before core facts. The chi square tests show there are frequency/percentage differences, but overall the patterns are similar, with no statistically significant differences in the AJA and AJE.

\section{Discussion and Conclusion}

The findings of this study indicated that Al Jazeera tended to reflect professional values to a substantial degree in its production of the news - just under the high level on the professional model index established for 
this study. There are many potential explanations that might clarify why Al Jazeera's content is more likely to embed professional values than marketing or cultural values in the production of the news.

\section{Political Liberalization and Modernizing the Media Environment}

The first point that explains the level of professionalism in AJ is related to the nature of the political and economic incubator environment for Al Jazeera. Media is the face of a democracy (Krimsky, 1997). For a media organization to be able to perform its democratic mission, it needs an incubator environment that accommodates freedom of expression. Professionalism is rarely spread in countries or societies where media are run and controlled by governments (Shoemaker \& Reese, 1996) such as in China, Russia, and the Middle East countries. So, what makes Qatar an exception-from other countries in the Middle East?

Al Jazeera was launched in 1996 as a sign of openness and as part of moving to democracy and political liberalization ideology (Bahry, 2001). In fact, the former Emir undertook wide-ranging reforms to prepare the genuine environment to accommodate and facilitate Al Jazeera's role in shaping and directing the Arab awareness. For example, the Ministry of the Information was cancelled; this eventually meant no censorship on media content anymore. Qatar government hired the most well-trained and professional staff from Arabic $\mathrm{BBC}$ to enable AJ to achieve its organizational goals. On the political level, despite the Arab decision of boycotting normalization with Israel, Doha agreed to open Israeli trade representative office in September 1996; this move helped AJ to move freely to achieve its objectivity and fairness when presenting the two sides on the historical Arab-Israeli conflict. Further, approving the permanent constitution that provides the real press freedom and political reform, establishing the Central Municipal Council and electing its members, giving women the right to run for election and voting are also aspects of liberalizing Qatar. Moreover, hosting foreign branches of Western and American universities in Qatar are also part of the Qatari liberalization and openness move. These kinds of moves at different levels have contributed to creating a solid and fertile basis for enabling AJ to operate in a relatively freer environment which reflects directly on producing content with professional values.

The results of this study that Al Jazeera employs more professional values in its news production also consistent with what other scholars found about the role of AJ in promoting democracy in the region of the world with the most dictatorships, adopting professional and Western journalism values in reporting, and expanding the margins of freedom of expression and speech among Arab audience (e.g., Quinn \& Walters).

\section{Al Jazeera's Mission, Vision, and Values}

Second, AJ's main mission and its organizational values match the core assumption of the professional model. Al Jazeera on the top of its organization agenda insists to uphold these professional values in doing its reports. For example, in its Arabic version and under "About" icon, AJ identifies itself as Arabic media service affiliation with global orientation and adopts the motto of "Opinion and the Other Opinion", the motto reflects a desire for pluralism, and inclusion of global views that transcend the Arab region. Also, AJE in its Vision, Mission and Values icon on its website identifies its main purpose to "maintain credibility through impartial, accurate and comprehensive representation of the story" (Al Jazeera English website, 2014). Thus, the main goal of $\mathrm{AJ}$ is to be an objective network and produce more professional content to its audience and this main goal matches with the findings of other scholars (e.g., Boyd-Barrett \& Xie, 2008; El-Nawawy \& Iskandar, 2003; Quinn \& Walters, 2004; Zeng \& Tahat, 2012) who found that AJ is free, independent, objective and adopting Western professional values in news production. The top editorial leaders in both AJE and AJA have insisted 
that Al Jazeera has a completely independent editorial policy from the Qatari government, which has nothing to do with the content (Attard, 2012).

\section{Al Jazeera and its Media Practices}

The third possible explanation of why AJ has more likely adopted professional values in the production of the news is related to the nature of Al Jazeera's practices. Sometimes it is not enough to claim that a news organization seeks to adhere to the professional values if its actions on the ground don't match its words. Many possible evidences can be shown here to prove how AJ's practices reflect its tendency to uphold the professional values in news production.

First, it may be that Al Jazeera doesn't care about other governments' desires, but gives priority to tell its readers story with facts. If professional values are not a priority on Al Jazeera's agenda, then it will report the way Qatar's neighbors want. However, Al Jazeera has never stopped criticizing other Arab governments, and has broken all types of taboos in its daily coverage (Abudl-Mageed \& Herring, 2008; Bahry, 2001; Lynch, 2005; Quinn \& Walters, 2004). Al Jazeera coverage of the Arab world forced many Arab governments to shut down Al Jazeera bureaus (Seib, 2011), and excluded it from being a member of the Arab States Broadcasting Union (Miles, 2005). The findings of this study correspond with the third attribute of profession in Beam, Weaver and Brownlee's (2009) study: When a news organization "put public service interests ahead of economic gain" (p. 279). Second, it may be that Al Jazeera upholds its long-term philosophy of maintaining "the right to speak up" (Al Jazeera English website, 2014) by allowing people to express their opinion freely, encouraging debates, viewpoints and counter viewpoints. Al Jazeera seeks to express a diversity of views, from both within and outside the Arab world. Al Jazeera has given voices to ordinary people in the street to express their grievances and ambitions. Many guest speakers from different schools of thought were interviewed, and many Arab opposition representatives have also been given the chances to debate and present their opinions, ideas and thoughts freely on the most pressing issues in the Arab world. These kinds of actions enable AJ to perform its main role in promoting democracy and expanding the margins of freedom in the region. The names of its most famous talk shows reflect its core professional mission stated in its slogan "Opinion, and the other opinion": e.g., More Than One Opinion, The Opposite Direction, Open Dialogue, No Limits (Lynch, 2005). By focusing on the common interests of the public and providing different perspectives on these issues that impact on the society and the public life, $\mathrm{AJ}$ in this role is consistent with the logic of the concept of public service, which is considered one of the most important professional values in libertarian and social responsibility theories. Finally, it may be that Al Jazeera was the first Arab and Muslim news organization that allows Israelis to appear in its airtime news bulletins and conducts live interviews with them (Boyd-Barrett \& Xie, 2008). Allowing Israelis to presents their opinions matches with the logic of fairness value in professionalism.

\section{Al Jazeera and its Well-Trained Staff}

Al Jazeera's Western-professional and well-trained journalists are the fourth factor that might explain why AJ upholds professional values in the production of the news. The Al Jazeera network founders decided to hire 120 of these Western-professional and well-trained journalists in its team (Bahry, 2001; El-Nawawy \& Iskandar, 2003; Lynch, 2005). Al Jazeera has strong professional values that make it more objective (Fahmy \& Al Emad, 2011). Al Jazeera inherited the BBC network's editorial "spirit, freedom, style, and adapted Western journalistic values" (El Nawawy, 2003; Scott, 2003). Having a well-qualified and well-trained staff will help AJ to achieve its organizational goals of producing well-balanced and more professional values content. 


\section{Conclusion}

This study has intended to contribute in establishing an international journalism model in the production of the news to find out which news values are more prevalent in non-Western newsroom when the same news organization communicates to two or more audiences that have different cultural, social, language, and interest backgrounds. The study came up with these importation conclusions:

Al Jazeera, at the larger level (both AJA and AJE) attempts to provide professional news coverage that reflects more professional values in the production of news. Most of these values are consistent with the logic of both the libertarian and the social responsibility theories in Western journalism. Al Jazeera has a tendency to be objective, fair, and present more perspectives on the same issue from different sources. While the professional model in journalism has grown and thrived especially in democratic societies, Al Jazeera, by adopting professional values in reporting, has to be treated in a completely different way. Al Jazeera emerged in a very complicated geopolitical context, where freedom of expression is the last priority in the agenda of the Middle Eastern governments.

\section{Scholarly and Practical Implications}

This study is contributing conceptually and hopefully laying the groundwork for future studies. For the first time, this study tested different related concepts together that comprise large construct "professionalism" in the relationship between media content and media creator. Most studies done before this study tested professionalism by using and examining only one variable such as objectivity or fairness and balance, etc. However, this study established a professional model comprising multiple variables that could be tested together to judge whether or not the news content reflects more or less professional values or other values.

Further, this study contributes in overcoming personal impressions and non systematic ways of judging any news organization, by developing a scientific approach based on testing the content of any news organization through applying this professional model; researchers or observers will be able to judge/interpret what values were more prevalent in news production.

\section{Limitations}

As with all research, this study does have some shortcomings. First of all, the study focused on the content drawn from one influential global news producer with the highest readership. Other websites may display different features and follow different patterns when reporting on different issues. Another limitation is related to the time frame of the study. The study analyzed Al Jazeera coverage from January 1, 2014-April 30, 2014. Therefore, the coverage may reflect media reaction to unique events during the period, such as Arab Spring. Future studies can expand the time to include more weeks from different months of the year. Therefore, the generalizability of this sample is limited to the extent to the four months from where the sample was drawn. Another limitation is related to using content analysis as an indicator of the influence of professional values without directly seeking the perspectives of Al Jazeera journalists about how they think about or apply these values.

\section{Future Studies}

This research suggests several directions for future investigations. Comparison studies are beneficial and necessary in this field. The focus of this study was on how the same news organization uses different contents to communicate to different audiences. This model could be used to measure different media contents that also target the same audience (French or Arabic or Persians, etc.) by different news organizations (e.g., CNN, BBC, Al Jazeera, etc.). 
Finally, this model could expand cooperation between scholars, academics, and graduate students in journalism and mass communication colleges around the world. First, they might use this model on media content that published in the same language. Second, this type of cooperation between scholars and researchers from different journalism schools in the globe could help to overcome the language barriers in studying media content. In this point, hypothetically, four researchers from four countries could shape a research team to analyze, for example, four websites produced by BBC that communicates with four different audiences (e.g., French BBC, Arabic BBC, English BBC, and Persian BBC). In this example, a researcher from France could apply this model by analyzing the French BBC content, a researcher from Jordan could apply the same coding system on the Arabic BBC content, an Iranian researcher might apply the analysis on the Persian BBC content, and a Canadian researcher might also apply the same procedures on the English version of the BBC to find out the extent to which these professional values are prevalent in media content produced by the same news organization.

\section{References}

Abdul-Mageed, M., \& Herring, S. (2008). Arabic and English news coverage on aljazeera.net. Proceedings of Cultural Attitudes Towards Technology and Communication (pp. 271-285).

Ajami, F. (2001). What the Muslim world is watching. Retrieved from http://www.nytimes.com/2001/11/18/magazine/18ALJAZEERA.html

Al Jazeeera. (2013). About Al Jazeera America. Retrieved from http://america.aljazeera.com/tools/about.html

Bahry, L. (2001). The new Arab media phenomenon: Qatar's Al Jazeera. Middle East Policy, 8(2), 88-99.

Beam, R., Brownlee, B., Weaver, D., \& Cicco, D. (2009). Journalism and public service in troubled times. Journalism Studies, 10(6), 734-753.

Beam, R., Weaver, H., \& Brownlee, J. (2009). Change in professionalism of U.S. Journalists in the turbulent twenty-first century. Journalism \& Mass Communication Quarterly, 86(2), 277-298.

Boyd-Barrett, J., \& Xie, S. (2008). Al Jazeera, Phoenix satellite television and the return of the state: Case studies in market liberalization, public sphere and media imperialism. International Journal of Communication, 2, 206-222.

Campagna, J. (2001). Between two worlds: Qatar's Al Jazeera satellite channel faces conflicting expectations. Retrieved from http://cpj.org/reports/2001/10/aljazeera-oct01.php

Condit, C., \& Selzer, J. A. (1985). The rhetoric of objectivity in the newspaper coverage of a mureder trial. Critical Studies in Mass Communication, 2(3), 197-216.

Darwish, A. (2001). Bin Laden's TV choice. The Times (p. 22).

Deuze, M. (2005). What is journalism? Professional identity and ideology of journalists reconsidered. Journalism, 6(4), $442-464$.

El- Nawawy, M., \& Powers, S. (2008). Mediating conflict: Al Jazeera English and the possibility of a conciliatory media. Los Angeles, CA: Figueroa Press.

Elareshi, M., \& Gunter, B. (2012). Patterns of news media consumption among young people in Libya. Journal of African Media Studies, 4(2), 173-191.

El-Nawawy, M., \& Iskandar, A. (2003). Al-Jezeera: The story of the network that is rattling governments and redefining modern journalism. Boulder, CO: Westview Press.

Fahmy, S., \& Al-Emad, M. (2011). Al-Jazeera versus Al-Jazeera: A comparison of the network's English- and Arabic-online coverage of the U.S./Al Qaeda conflict. International Communication Gazette, 73(3), 216-232.

Foote, J. (1995). Stand point: The structure and marketing of global television news. Journal of Broadcasting \& Electronic Media, 39(1), 127-133.

Foote, J., \& Gade, P. (2006). Voice of America content study. Gaylord College of Journalism and Mass Communication, the University of Oklahoma.

Gade, P. (2011). Postmodernism, uncertainty, and journalism. In W. Lowrey, \& P. Gade (Eds.), Changing the news: The forces shaping journalism in uncertain times. New York, NY: Routledge.

Gade, P., \& Lowrey, W. (2011). Reshaping the journalistic clutre. In W. Lowrey, \& P. Gade (Eds.), Changing the news: The forces shaping journalism in uncertain times. New York, NY: Routledge. 
Galal, A., Galander, M., \& Auter, P. (2008). The image of the United States portrayed in Arab World online journalism. Proceedings from Ninth International Symposium on Online Journalism. University of Texas at Austin.

Hitchens, L. (2007). Deconstructing journalism culture: Toward a universal theory. Communication Theory, 17, $367-385$.

Kovach, B., \& Rosenstiel, T. (2007). The elements of journalism: What news people should know and the public should expect. New York: Three Rivers Press.

Lynch, M. (2005). Watching Al Jazeera. The Wilson Quarterly, 29(3), 36-45.

Massey, B. L., \& Levy, M. R. (1999). Interactivity, online journalism and English-language web newspapers in Asia. Journalism and Mass Communication Quarterly, 76, 138-151.

Merrill, J. C. (1974). The imperative of freedom: A philosophy of journalistic autonomy. New York: Hastings House.

Miles, H. (2005). Al Jazeera: The inside story of the Arab news channel that is challenging the west. New York: Grove Press.

Mody, B. (2012). The marketization of foreign news. Global Media and Communication, 8(2), 99-115.

Munoz-Torres, J. (2007). Underlying epistemological conceptions in Journalism. Journalism Studies, 8(2), 224-247.

Negus, S. (2001). Letter from Cairo-Egypt's political agenda is increasingly set by the viewpoints aired on Al Jazeera. The Nation, 273(16), 17-18.

Peterson, S. (1979). Foreign news gatekeepers and criteria of newsworthiness. Journalism Quarterly, 56(1), 116-125.

Peterson, T. (1956). The social responsibility theory of the Press. In F. Siebert, T. Peterson, \& W. Schramm (Eds.), Four theories of the press (pp. 87-92). Urbana, IL: University of Illinois Press.

Quinn, S., \& Walters, T. (2004). Al Jazeera: A broadcaster creating ripples in a stagnant pool. In R. D. Berenger (Eds.), Global media go to war (pp. 57-71). Spokane, WA: Marquette Books.

Reese, S. D. (1990). The news paradigm and the ideology of objectivity: A socialist at "The all Street Journal". Critical Studies in Mass Communication, 7(4), 390-409.

Riffe, D., Lacy, S., \& Fico, F. (2005). Analyzing media messages: Using quantitative content analysis in research. Mahwah, N.J.: Lawrence Erlbaum.

Seib, P. (2011). Al Jazeera English in focus. Public Diplomacy Magazine, 6, 19-23.

Shoemaker, P. J., \& Reese, S. D. (1996). Mediating the message: Theories of influences on mass media content (2nd ed.). White Plains, N.Y.: Longman.

Simon, T., Fico, F., \& Lacy, S. (1989). Covering conflict and controversy: Measuring balance, fairness, defamation. Journalism Quarterly, 66(2), 427-33.

Suhudson, M. (2001). The objectivity norm in American journalism. Journalism, 2, 149-170.

Weaver, D. H., Beam, R. A., Brownlee, B. J., Voakes, P. S., \& Wilhoit, G. C. (2007). The American Journalist in the 21st Century: U.S. news people at the dawn of a new Millennium. Mahwah, NJ: Lawrence Erlbaum Associates.

Wimmer, R., \& Dominick, J. (2011). Mass media research: An introduction (9th ed.). Thomson, CA.

Wojcieszak, M. (2007). Al Jazeera a challenge to traditional framing research. The International Communication Gazette, 69(2), 115-128.

Zednik, R. (2002). Perspectives on war: Inside Al Jazeera. Columbia Journalism Review, 40(6), 44-47.

Zeng, L., \& Tahat, K. (2012). Picturing terrorism through Arabic lenses: A comparative analysis of Al Jazeera and Al Arabiya. Asian Journal of Communication, 22(5), 433-448. 